\title{
Article
}

Mycosphere

\section{Muscodor camphora, a new endophytic species from Cinnamomum camphora}

\author{
Meshram $V^{1,2}$, Kapoor $N^{3,}$ Chopra $G^{3}$, and Saxena $S^{4^{*}}$ \\ ${ }^{1}$ Department of Biotechnology, Thapar University, Patiala, Punjab 147004 India \\ ${ }^{2}$ Present address: Department of Biochemistry, DAV University, Jalandhar, Punjab 147004 India \\ ${ }^{3}$ Department of Biotechnology, Thapar University, Patiala, Punjab 147004 India \\ ${ }^{4}$ Department of Biotechnology, Thapar University, Patiala, Punjab 147004 India
}

Meshram V, Kapoor N, Chopra G, Saxena 2017 - Muscodor camphora, a new record from Cinnamomum camphora. Mycosphere 8(4), 568-582, Doi 10.5943/mycosphere/8/4/6

\begin{abstract}
The current study describes a new endophytic species Muscodor camphora from internal stem tissue of Cinnamomum camphora. The fungus produces white hairy colonies over potato dextrose agar medium with sterile ropy mycelial filaments and hyphal coils. Scanning electron micrographs exhibited that they form dense hyphal web, which club to form rope-like mycelium and coils. Phylogenetic, genetic distance and haplotype analyses based on internal transcribed spacer confirm its identity as a new species in the genus Muscodor. The fungus also produces a unique mixture of 18 volatile organic compounds predominantly producing tetracontane, 4-octadecylmorpholine, $\mathrm{N}, \mathrm{N}$ dimethyl-1-pentadecanamine and cis-9-hexadecenal. These volatiles exhibited synergistic inhibitory effect over a tested spectrum of pathogenic microorganisms. Out of 15 tested pathogenic microorganisms, the volatile organic compounds inhibit the growth of fungal pathogens by 13-70\%, while considerable inhibition was observed against Candida, Staphylococcus and Pseudomonas species.
\end{abstract}

Key words - ITS-rDNA, ropy mycelium, Tiger Hills, volatile organic compounds

\section{Introduction}

Over the last two decades, it has become evident that plants hold enormous diversity of microorganisms within their tissues referred to as 'endophytes' (Arnold et al. 2001, Schulz \& Boyle 2005, Strobel 2006, Murali et al. 2007, Hyde \& Soytong 2008, Rodriguez et al. 2009, Peay et al. 2010). Endophytes have been recognised as promising sources of bioactive compounds as well as putative phytochemicals such as ambuic acid, camptothecin, isopestacin and paclitaxel which find applications in medicine, industry and agriculture (Strobel \& Daisy 2003, Suryanarayanan et al. 2009, Gutierrez et al. 2012). Muscodor is a genus of sterile, volatile producing endophytic fungi with antimicrobial properties (Strobel et al. 2001, Zhang et al. 2010). The genus came into existence after the discovery of Muscodor albus, an endophytic fungus isolated from the branch of Cinnamomum zeylanicum growing in the Lancetilla Botanical garden in Honduras (Worapong et al. 2001). Unique to the genus was its sterility and musky odour attributed to mixture of volatile organic compounds (VOCs) produced by it which possessed potential antimicrobial activity for its use as a mycofumigant (Strobel et al. 2001). 
Since then, this genus has gradually expanded and to date 18 species have been described based on their morphological and cultural characteristics like formation of ropy mycelium, right angle branching and cauliflower like or nondescript structures, genetic makeup and VOCs produced by them (Worapong et al. 2001, 2002, Daisy et al. 2002, Mitchell et al. 2008, Gonzalez et al. 2009, Zhang et al. 2010, Suwannarach et al. 2010, Kudalkar et al. 2012, Meshram et al. 2013, 2014, Saxena et al. 2014, 2015). Muscodor spp., are of immense value as they possess biological control properties by virtue of the admixture of VOCs produced by them which have lethal effects against plant as well as human pathogenic microbes, insects and nematodes (Strobel et al. 2001, Schnabel \& Mercier 2006, Mercier et al. 2007).

Mycofumigation with Muscodor has been done to control the decay of fruits like apples, peaches, strawberries and lemon (Mercier \& Smilanick 2005, Gabler et al. 2006, Schnabel \& Mercier 2006). The VOCs produced by Muscodor has also been utilized as a soil fumigant to stop damping off and root rot in plants (Stinson et al. 2003, Suwannarach et al. 2015). Further, Muscodor also helps in controlling building molds and sewage treatment (Strobel 2006). Hence exploration of new isolates and taxa of Muscodor is of great interest in exploiting the concept of mycofumigation for multipurpose applications ranging from agriculture to humans.

Muscodor species have been found in endophytic association with various cinnamon plant species (Strobel et al. 2001, Suwannarach et al. 2010, 2013, Saxena et al. 2014, Meshram et al. 2014, 2015). Based on these earlier reports, we undertook a systematic survey to explore the presence of Muscodor species in Cinnamomum camphora plant growing in rain forest areas of North-eastern Himalayas. In this article, we describe a novel endophytic fungus Muscodor camphora (\#1639 CCSTITD) based on morphological/cultural characteristics, phylogenetic analysis and VOCs profile.

\section{Materials \& Methods}

\section{Plant Sample collection and fungal isolation}

Healthy and mature plant parts (leaf and stems) of Cinnamomum camphora were collected from the Tiger hill area, Darjeeling, West Bengal during March 2011. Plant samples were kept in sterile packets and stored at $4 \mathrm{C}$ till further use. The fungal isolation was done using Muscodor albus cz620 as a screening tool as reported by Ezra et al. (2004). Briefly, Potato Dextrose Agar (PDA) was poured into one quadrant of the four sectioned commercially available Petri dish. An actively growing agar plug of $M$. albus cz620 was placed over the PDA medium while other quadrants of the petriplates contained water agar (WA). The plates were then incubated at $24{ }^{\circ} \mathrm{C}$ for four days for VOCs production by $M$. albus cz620. The plant samples $(5 \mathrm{~cm})$ were washed under running tap water; air dried. The plant segment was surface sterilized using $2 \%$ sodium hypochlorite (v/v) for 3 minutes followed by $70 \%$ ethanol (v/v) for 1-2 minutes and $30 \%$ ethanol (v/v) for $45 \mathrm{~s}$ under a laminar flow hood. The surface sterilized plant segments were cut into small fragments of 2-3 $\mathrm{mm}$ and were then placed in the other quadrants containing WA thereby exposing the plant segments to VOCs of $M$. albus arising in the plates. The fungi emerging out of the host tissue was aseptically sub-cultured onto a fresh PDA plate so as to obtain pure isolates which were further preserved on PDA slants supplemented with $10 \%$ glycerol (Ezra et al. 2004, Strobel et al. 2007, Mitchell et al. 2008). The metabolically active form of the culture was submitted to the National Fungal Culture Collection of India, Agharkar Research Institute, Pune, India (NFCCI 3236)

\section{Morphotaxonomy}

Culture characteristics of $M$. camphora were studied by growing the fungus on three different media comprising of PDA, WA and SNA (Synthetischer Nahrstoffarmer Agar). Morphotaxonomic studies of the endophytic fungal isolate was done by mounting the culture in lactophenol cotton blue and then observing under a Nikon Stereozoom microscope (Nikon SMZ 745 T) coupled with NIS element D 3.2 software and a Nikon Eclipse Compound microscope (E100). Micrometry was done using ocular and stage scale and further confirmed by Image $\mathrm{J}$ software with at least 30 observations per structure. Culture characteristics including appearance, colour, growth rate, pigment and VOCs 
production along with its microscopic structures like hyphal characteristics and other cellular bodies were minutely observed and recorded (Mitchell et al. 2008, Meshram et al. 2013).

\section{DNA isolation, sequence assembly and phylogenetic analysis}

Total fungal genomic DNA isolation was carried out with the Wizard® Genomic DNA purification kit (Promega, Madison, WI, USA USA) as per instructions of the manufacturer. The phylogenetic relationship was established by using $M$. albus specific primers (M. albus Forward (5'GGGAGGCTACCCTATAGGGGATAC-3') and $M$. albus Reverse (5'-CAGGGGCCGGAACCAC TACAGAGG-3')) as described by Ezra et al. (2010). Amplification reaction was performed in a 25 $\mu 1$ reaction volume consisting of $50 \mathrm{ng}$ of extracted genomic DNA, $25 \mathrm{mM} \mathrm{MgCl} 2,2.5 \mathrm{mM} \mathrm{dNTP}$, $10 \mathrm{pmol} / \mu \mathrm{l}$ of each primer, $1.5 \mathrm{U}$ of Taq DNA polymerase in $10 \times$ Taq buffer. Thermal cycling parameters were initial denaturation at $96 \mathrm{C}$ for 5 minutes followed by 35 cycles of $95 \mathrm{C}$ for 45 seconds, $60 \mathrm{C}$ for 45 seconds, $72 \mathrm{C}$ for 45 seconds, followed by final extension at $72{ }^{\circ} \mathrm{C}$ for 5 minutes. Amplicon of approximately 400-500 bp was purified using Wizard® SV gel and PCR clean up system kit (Promega, Madison, WI, USA) according to the manufacturer's protocol. The amplified product was sequenced at Chromus Biotech Pvt. Ltd, Bangalore, India.

The obtained chromatograms were manually edited and checked using Sequencher ver. 5 (www.genecodes.com) and submitted in the GenBank under the accession number KC481681. The final consensus sequence was subjected to BLAST similarity search to ascertain putative positional homology with closely related organisms. The sequences of already reported Muscodor sp. along with Xylaria sp. were retrieved from GenBank and aligned with sequence of $M$. camphora by CLUSTAL W in MEGA 5 (Tamura et al. 2011). Gaps were treated as missing data. The phylogeny was inferred by using Neighbour-Joining method (Saitou \& Nei 1987). The evolutionary distances were computed using p-distance method (Nei \& Kumar 2000) and are in the units of the number of base differences per site. 1000 bootstrap replicates were taken to assess the clade stability.

The genetic relatedness of Muscodor camphora with previously reported Muscodor species was established by determining the pair wise distances implemented in MEGA 5. Analyses were conducted using the Maximum Composite Likelihood model. The rate variation among sites was modelled with a gamma distribution (shape parameter $=5$ ). All positions containing gaps and missing data were eliminated. There was a total of 359 positions in the final dataset. The resulted values are listed in Table 2. Genetic distance is the proportion (p) of nucleotide sites at which two sequences being compared are different from each other (Meshram et al. 2013). Further, the levels of DNA polymorphism such as number of variable sites $(\eta)$, haplotypes, haplotype diversity, nucleotide diversity $(\pi)$, evolutionary models were deduced with DNASp5 (Librado \& Rozas 2009, Meshram et al. 2013).

\section{Scanning Electron microscopy}

Scanning electron microscopy (SEM) of M. camphora was carried out as previously described by Ezra et al. (2004). Agar blocks of 10-day old fungus were placed in $2.5 \%$ glutaraldehyde in 0.1 $\mathrm{M}$ phosphate buffer ( $\mathrm{pH} 7.2$ ) overnight at $4 \mathrm{C}$ for fixation. The next day, it was washed with $0.1 \mathrm{M}$ phosphate buffer ( $\mathrm{pH}$ 7.2) twice. Subsequently, the fungal material was dehydrated by using acetone gradient series (30\%-100\% for 10 min each), and brought to critical point drying using Hexa-methyldisilazane (Sigma Aldrich, St. Louis, Missouri USA). The dehydrated sample was coated with gold palladium using a sputter coater. The images were then taken in high vacuum mode using Zeiss Evo40 (Carl-Zeiss, Oberkochen, Germany) SEM with a magnification range in between $307 \mathrm{X}$ and $2.02 \mathrm{KX}$ at $15 \mathrm{kV}$ extra high tension (Ezra et al. 2004, Kudalkar et al. 2012).

\section{Volatile analysis of $M$. camphora}

The volatiles produced by the 10-day culture of $M$. camphora were entrapped using a solid phase micro-extraction (SPME) syringe with a stable flex fibre of 50/30 di-vinylbenzene/carboxen on polydimethylsiloxane (Supelco, Sigma Aldrich, USA) as described by Ezra et al. (2004). The fiber was exposed for $45 \mathrm{~min}$, by placing the SPME syringe after drilling a small hole with the help of 
sterile needle, to the air space above the fungus. Then the fiber with entrapped VOCs was injected in the Shimadzu QP 2010 + gas chromatograph with thermal desorption system TD 20 for 30 s. Fungal volatiles were separated by using RTX column (diphenyl 95\%, dimethyl polysiloxane $5 \%$ ) with 30 $\mathrm{m} \times 0.25 \mathrm{~mm}$ ID and $0.25 \mathrm{~mm}$ DF. The column was programmed at $100{ }^{\circ} \mathrm{C}$ for $2 \mathrm{~min}$ before the temperature was increased to $250 \mathrm{C}$ for 2 minutes and finally to $300 \mathrm{C}$ for 13 minutes. Helium was used as the carrier and the initially the column head pressure was $94.4 \mathrm{KPa}$. Data acquisition and processing was done on GCMS solution software. The compounds obtained after GC/MS analysis was then subtracted from the control plate consisting only PDA medium. The obtained 18 compounds were then tentatively identified based on their high quality matching with database of National Institute of Standard and Technology (NIST) compounds (NIST05) and compared with all reported species of Muscodor (Ezra et al. 2004, Kudalkar et al. 2012)

\section{Bioassay of VOCs produced by M. camphora}

Antimicrobial activity of the volatiles produced by $M$. camphora was tested by using a bioassay method employing $90 \mathrm{~mm}$ Petri dish with PDA (Ezra et al. 2004, Mitchell et al. 2008). Agar strips $(1 \mathrm{~cm})$ were removed to create quadrants as well as to prohibit movement of any diffusible inhibitory compound from the Muscodor sp. to the test microorganism(s) comprising of Colletotrichum gloeosporioides, Rhizoctonia solani, Lasiodiplodia theobromae, Staphylococcus aureus, Staphylococcus epidermidis and Pseudomonas aeruginosa. Into one of the quadrant, an agar plug of actively growing $M$. camphora was placed. The plates were sealed and incubated at $26 \pm 1 \mathrm{C}$ for 5 days for VOCs production. Thereafter, individual test fungi were inoculated by placing a $3 \mathrm{~mm}$ plug of 7 day old culture on the rest of the quadrants. Bacteria and yeasts were tested by individual streaking in other quadrants. Correspondingly, the control plates comprised only inoculated test bacteria or fungi and were devoid of $M$. camphora, allowing it to grow normally. Antimicrobial action of VOCs was determined by monitoring the difference in the growth of microorganisms in test and control plates. All the tests were performed in triplicates and values calculated as mean \pm SD.

\section{Results}

Muscodor camphora Meshram V, Kapoor N, Chopra G \& Saxena S, sp. nov.

Fig. 1

MycoBank no.: MB 812282; GenBank no.: KC481681

Etymology - 'camphora' refers to host plant 'Cinnamomum camphora'.

Diagnosis - Differs from $M$. cinnamomi, $M$. sutura, $M$. crispans, $M$. darjeelingensis by absence of non-descript cauliflower like bodies. Varies from M. tigerii, M. equiseti and M. yucanteanensis by absence of swollen hyphae. Differs from M. strobelii, M. albus cz620 and M. vitigenus by presence of coiling structures. It does not produce any red or pink pigment like $M$. roseus and M. suthupensis.

Material examined - India, West Bengal, Darjeeling, Tiger Hills, $27^{\circ} 13^{\prime}-26^{\circ} 27^{\prime} \mathrm{N} 88^{\circ} 53^{\prime}-$ $87^{\circ} 59^{\prime}$ E, endophytic fungi from stem internal tissue of Cinnamomum camphora, 23 March 2011, leg. Sanjai Saxena (Holotype: CCSTITD \#1639; ex type NFCCI- 3236) rDNA sequence ex-holotype: KC481681

Description - Endophytic in internal tissue of stem of Cinnamomum camphora. The fungal colonies incubated at $26 \pm 1 \mathrm{C}$ for 10 days with 12 hours of photoperiod on PDA grow moderately with mean colony diameter of $65.4 \pm 1.2 \mathrm{~mm}$ (Figs $1 \mathrm{a}-\mathrm{b}$ ). Colonies front and reverse both were white in color, floccose, smooth margined with thick hairy aerial mycelium. Hyphae $3.5 \pm 0.7 \mu \mathrm{m}$ thick, fused to form rope like hyphal strands with branching at right angle (Fig. 1c). The fungus produced VOCs with fruity smell. The fungus exhibited a variation in colony morphology when grown on different media. Over SNA and WA, the culture formed hyaline colonies which were slow to moderately growing with a mean colony diameter of $58.19 \pm 0.91 \mathrm{~mm}$ and $36.62 \pm 1.23 \mathrm{~mm}$ respectively after 10 days of incubation. Microscopic studies revealed that hyphal fabrication was septate and branched at right angle. The average width of the hyphae over SNA and WA medium was $3.16 \pm 0.77 \mu \mathrm{m}$ and $3.1 \pm 0.63 \mu \mathrm{m}$ respectively. Over SNA and WA, the hyphae branched and terminates into coils which were (27.19)-47.41 $\pm 13.08-(66.93) \mu \mathrm{m}$ and (37.3)-49.35 \pm 14.17-(73.76) 
$\mu \mathrm{m}$ wide (Figs 1d-f). The fungal isolates did not produce any VOCs over SNA and WA. Spores and fruiting bodies did not develop under any of the tested conditions.
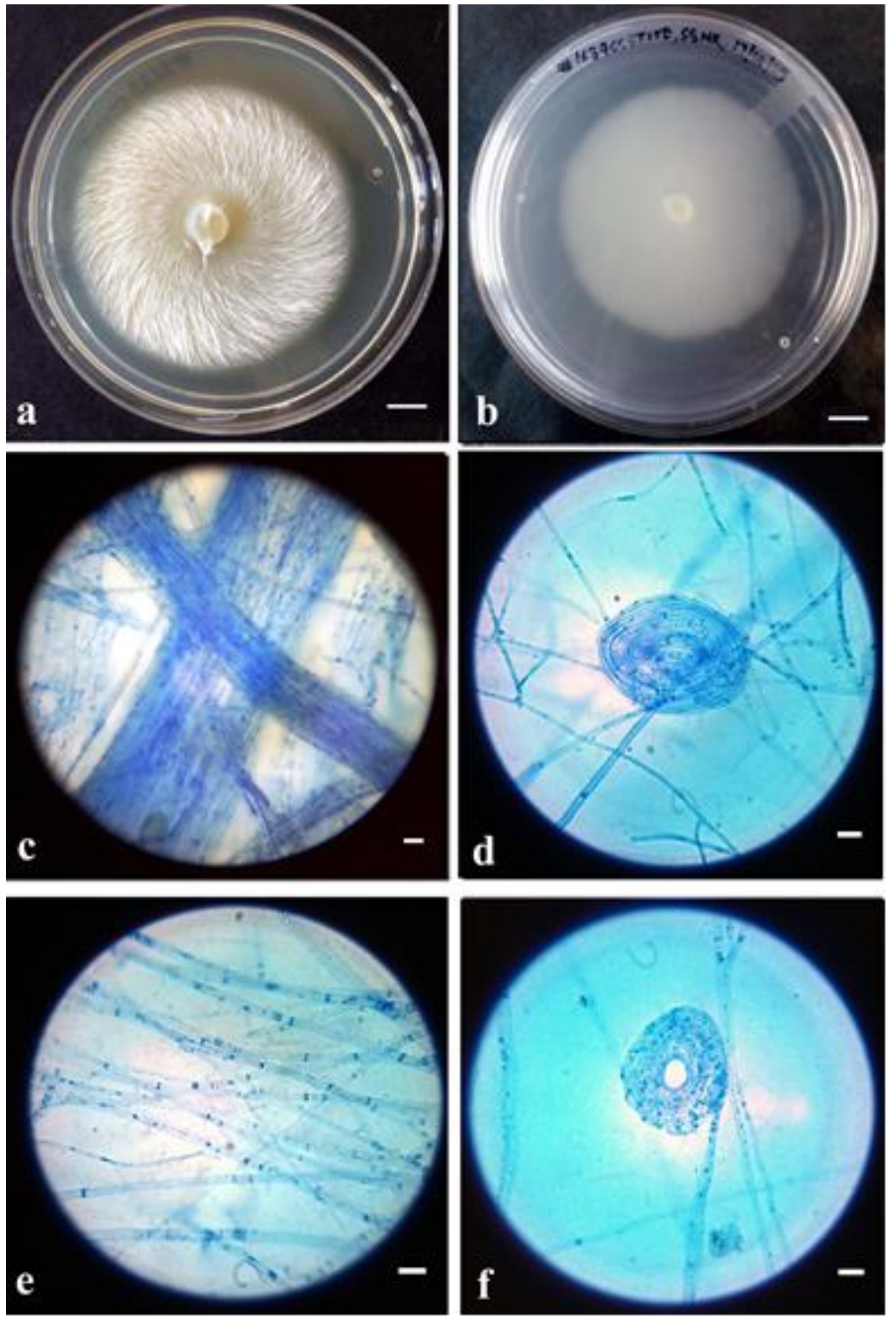

Figure 1 - Morphological traits of Muscodor camphora (\#1639 CCSTITD). a Morphological features, front view over PDA. b Reverse view. c Ropy mycelium. d Coil formation of fungal hyphae over SNA medium. e Hyphae over WA medium. f Hyphal coil over WA medium. Scale bars: $\mathrm{a}-\mathrm{b}=$ $10 \mathrm{~mm}, \mathrm{c}-\mathrm{f}=10 \mu \mathrm{m}$

\section{Phylogenetic analysis}

The evolutionary relationship and dynamics of $M$. camphora was represented by ITS region sequence analysis. The BLAST search showed $98 \%$ sequence similarity with M. crispans, M. musae, M. oryzae, M. roseus, M. albus, $M$. cinnamomi and $M$. kashayum. It also exhibited $96 \%$ similarity with $M$. tigerii and $M$. darjeelingensis and $95 \%$ similarity with $M$. suthepensis, $93 \%$ similarity with M. strobelii. Representative ITS sequences of Muscodor species and two species of was taken from NCBI database for the pictorial phylogenetic tree representation (TreeBASE reviewer access URL: http://purl.org/phylo/treebase/phylows/study/TB2:S20515?x-access-code=cf3f3db6e76f819db1264 cdd25aa55d9\&format=html). The neighbour joining tree resolved into three separate clades. Clade I clustered M. albus, M. cinnamomi, M. oryzae, M. darjeelingensis, M. musae, M. kashayum, M. suthepensis, M. roseus, $M$. strobelii along with M. camphora. M. strobelii and M. camphora clustered basal to the clade thereby confirming the novelty of M. camphora. Clade II clustered M. sutura, M. 
equiseti, M. vitigenus, M. yucatanensis and Clade III clustered M. fengyangensis species. Xylaria mali and Xylaria arbuscula formed a separate clade basal to all the three clades. Taphrina sadebeckii was chosen to root the tree (Fig. 2).

The number of polymorphic sites $(\eta)$, nucleotide diversity $(\pi)$ and number of haplotypes of ITS region are shown in Table 1. All Muscodor species were grouped in 11 haplotypes. The ITS region exhibited a $19.6 \%$ of nucleotide variation. p-distance of all nucleotide sites of the ITS region sequence comparisons between all the known species of Muscodor sp. and Muscodor camphora (Table 2) was showing data concordant to that of phylogenetic as well as DNA polymorphism data thereby indicating that $M$. camphora is different from other existing species of Muscodor. Thus, it can be concluded that $M$. camphora is a new addition to Muscodor genus.

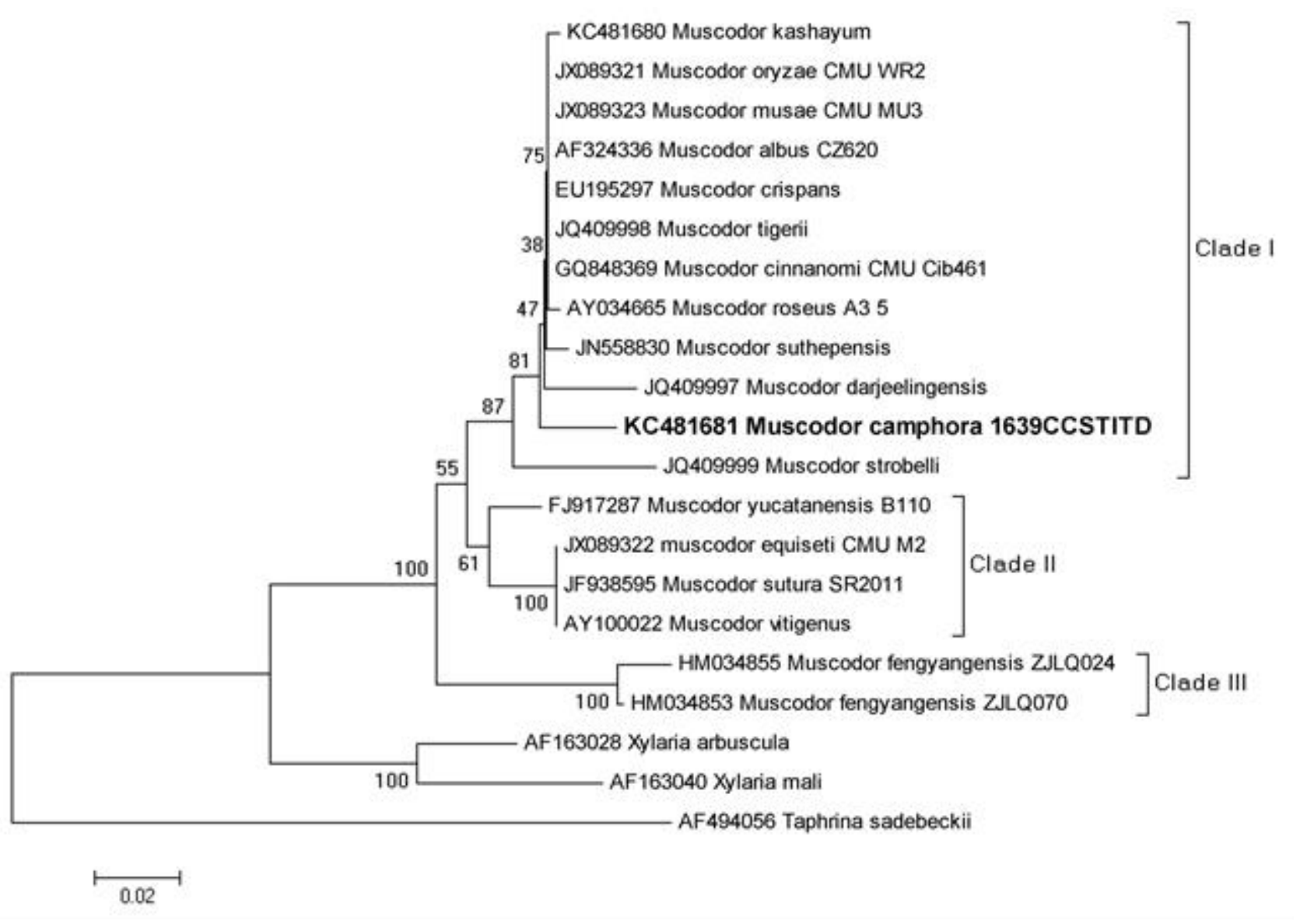

Figure 2 - The neighbour-joining tree based on ITS1-5.8S-ITS2 region. The optimal tree with the sum of branch length $=0.0 .554$ is shown. The percentage of replicate trees in which the associated taxa clustered together in the bootstrap test (1000 replicates).

\section{Scanning electron microscopy}

The scanning electron micrographs of $M$. camphora exhibited the true features of Muscodor species forming long, sterile ropy mycelium that terminates into coils which branches at right angle. The hyphae further fuse to form ropy mycelium (Fig. 3). M. camphora exhibited variation in morphology from the other type strains of Muscodor Morphologically, Muscodor camphora is different from $M$. cinnamomi M. sutura, $M$. crispans which exhibit a cauliflower like sterile structure and possesses ropy coiled mycelia. M. yucatanensis, M. equiseti and $M$. tigerii has a ropy structure with swollen hyphae whereas Muscodor albus, M. strobelii only exhibits a ropy mycelium without any hyphal coils hence making it different from M. camphora. Muscodor roseus has a dense rose coloured mycelium making it remarkably dissimilar from M. camphor. 
Table 1 Nucleotide properties of the ITS-rDNA region of the Muscodor camphora.

\begin{tabular}{|c|c|}
\hline Locus & ITS1-5.8S-ITS2 \\
\hline No. of sites & 758 \\
\hline No. of polymorphic sites $(\eta)$ & 149 \\
\hline No. of haplotypes & 11 \\
\hline \multirow{11}{*}{ Haplotype } & 1 [ JQ409999 (M. strobelii)] \\
\hline & Hap_2: 1 [ JQ409999 (M. darjeelingensis)] \\
\hline & $\begin{array}{ll}\text { Hap_3: } & 6[\mathrm{JQ} 409998 \text { (M. tigerii), EU195297 (M. crispans) } \\
& \text { AF324336 (M. albus CZ620), JX089323 (M. musae), } \\
& \text { JX089321 (M. oryzae), GQ848369 }(\text { M. cinnanomi })]\end{array}$ \\
\hline & Hap_4: $1[$ KC481680 (M. kashayum) $]$ \\
\hline & Hap_5: $1[$ KC481681 (M. camphora)] \\
\hline & Hap_6: 1 [FJ917287 (M. yucatanensis)] \\
\hline & $\begin{array}{c}\text { Hap_7: } 3[\text { JX089322 (M. equiseti), JF938595 (M. sutura), } \\
\text { AY100022 (M. vitigenus)] }\end{array}$ \\
\hline & Hap_8: 1 [HM034855 (M. fengyangenensis ZJLQ024)] \\
\hline & 1 [HM034853 (M. fengyangenensis ZJLQ070)] \\
\hline & Hap_10: 1 [AY034665 (M. roseus)] \\
\hline & Hap_11: 1 [JN558830 (M. suthepensis)] \\
\hline Haplotype Diversity & $0.914 \pm 0.050$ \\
\hline Nucleotide diversity $(\pi)$ & 0.079 \\
\hline Tajima's D & Not significant \\
\hline Fu and Li's D* & Not significant \\
\hline Fu and Li's F* & Not significant \\
\hline
\end{tabular}

Table 2 p-Distance of nucleotide sites among the ITS sequences compared between Muscodor camphora, Xylaria and Muscodor spp.

\begin{tabular}{|c|c|c|c|c|c|c|c|c|c|c|c|c|c|c|c|c|c|c|c|c|}
\hline & 1 & 2 & 3 & 4 & 5 & 6 & 7 & 8 & 9 & 10 & 11 & 12 & 13 & 14 & 15 & 16 & 17 & 18 & 19 & 20 \\
\hline \multicolumn{21}{|l|}{ KC481681 } \\
\hline AF324336 & 0.016 & & & & & & & & & & & & & & & & & & & \\
\hline JQ409999 & 0.049 & 0.034 & & & & & & & & & & & & & & & & & & \\
\hline JQ409997 & 0.035 & 0.018 & 0.049 & & & & & & & & & & & & & & & & & \\
\hline JQ409998 & 0.016 & 0.000 & 0.034 & 0.018 & & & & & & & & & & & & & & & & \\
\hline KC481680 & 0.018 & 0.002 & 0.037 & 0.020 & 0.002 & & & & & & & & & & & & & & & \\
\hline EU195297 & 0.016 & 0.000 & 0.034 & 0.018 & 0.000 & 0.002 & & & & & & & & & & & & & & \\
\hline JX089323 & 0.016 & 0.000 & 0.034 & 0.018 & 0.000 & 0.002 & 0.000 & & & & & & & & & & & & & \\
\hline JX089321 & 0.016 & 0.000 & 0.034 & 0.018 & 0.000 & 0.002 & 0.000 & 0.000 & & & & & & & & & & & & \\
\hline FJ917287 & 0.044 & 0.029 & 0.056 & 0.049 & 0.029 & 0.032 & 0.029 & 0.029 & 0.029 & & & & & & & & & & & \\
\hline GQ848369 & 0.016 & 0.000 & 0.034 & 0.018 & 0.000 & 0.002 & 0.000 & 0.000 & 0.000 & 0.029 & & & & & & & & & & \\
\hline JX089322 & 0.046 & 0.032 & 0.061 & 0.051 & 0.032 & 0.034 & 0.032 & 0.032 & 0.032 & 0.022 & 0.032 & & & & & & & & & \\
\hline JF938595 & 0.046 & 0.032 & 0.061 & 0.051 & 0.032 & 0.034 & 0.032 & 0.032 & 0.032 & 0.022 & 0.032 & 0.000 & & & & & & & & \\
\hline AY100022 & 0.046 & 0.032 & 0.061 & 0.051 & 0.032 & 0.034 & 0.032 & 0.032 & 0.032 & 0.022 & 0.032 & 0.000 & 0.000 & & & & & & & \\
\hline HM034855 & 0.087 & 0.071 & 0.087 & 0.092 & 0.071 & 0.074 & 0.071 & 0.071 & 0.071 & 0.058 & 0.071 & 0.066 & 0.066 & 0.066 & & & & & & \\
\hline HM034853 & 0.077 & 0.061 & 0.077 & 0.082 & 0.061 & 0.064 & 0.061 & 0.061 & 0.061 & 0.046 & 0.061 & 0.053 & 0.053 & 30.053 & 0.011 & & & & & \\
\hline AY034665 & 0.018 & 0.002 & 0.037 & 0.020 & 0.002 & 0.004 & 0.002 & 0.002 & 0.002 & 0.032 & 0.002 & 0.034 & 0.034 & 0.034 & 0.073 & 0.064 & & & & \\
\hline JN558830 & 0.020 & 0.004 & 0.039 & 0.023 & 0.004 & 0.007 & 0.004 & 0.004 & 0.004 & 0.029 & 0.004 & 0.034 & 0.034 & 0.034 & 0.071 & 0.061 & 0.007 & & & \\
\hline AF163028 & 0.121 & 0.109 & 0.135 & 0.132 & 0.109 & 0.112 & 0.109 & 0.109 & 0.109 & 0.115 & 0.109 & 0.123 & 0.123 & 0.123 & 0.138 & 0.129 & 0.112 & 0.104 & & \\
\hline AF494056 & 0.316 & 0.302 & 0.316 & 0.332 & 0.302 & 0.306 & 0.302 & 0.302 & 0.302 & 0.306 & 0.302 & 0.318 & 0.318 & 0.318 & 0.335 & 0.331 & 0.305 & 0.301 & 0.293 & \\
\hline AF163040 & 0.138 & 0.129 & 0.165 & 0.153 & 0.129 & 0.132 & 0.129 & 0.129 & 0.129 & 0.138 & 0.129 & 0.144 & 0.144 & 0.144 & 0.162 & 0.153 & 0.129 & 0.123 & 0.056 & 0.319 \\
\hline
\end{tabular}


Table 3 GC/MS air-space analysis of the volatile compounds produced by $M$. camphora after 10 days incubation at $26{ }^{\circ} \mathrm{C}$ PDA using a solid-phase micro-extraction (SPME) fiber.

\begin{tabular}{llllll}
\hline $\begin{array}{l}\text { Retention } \\
\text { Time }\end{array}$ & $\begin{array}{l}\text { Peak } \\
\text { area (\%) }\end{array}$ & Possible name & $\begin{array}{l}\text { Similarity } \\
(\%)\end{array}$ & $\begin{array}{l}\text { Molecular } \\
\text { Formula }\end{array}$ & $\begin{array}{l}\text { Mass } \\
\text { (Da) }\end{array}$ \\
\hline 11.432 & 1.11 & Phenol, 2,4-bis(1,1- dimethylethyl)- & 90 & $\mathrm{C}_{14} \mathrm{H}_{22} \mathrm{O}$ & 206 \\
12.657 & 0.32 & Heptadecanal & 92 & $\mathrm{C}_{17} \mathrm{H}_{36}$ & 240 \\
13.121 & 5.03 & Decanoic acid, decyl ester & 72 & $\mathrm{C}_{20} \mathrm{H}_{40} \mathrm{O}_{2}$ & 312 \\
13.446 & 1.15 & 4-octadecyl- Morpholine & 95 & $\mathrm{C}_{22} \mathrm{H}_{45} \mathrm{NO}$ & 339 \\
13.724 & 1.36 & N,N-dimethyl-1-pentadecanamine & 97 & $\mathrm{C}_{17} \mathrm{H}_{37} \mathrm{~N}$ & 255 \\
14.080 & 0.25 & 3-butynylbenzene & 77 & $\mathrm{C}_{10} \mathrm{H}_{10}$ & 130 \\
14.138 & 0.77 & Tetrachlorohydroquinone dimethyl ether & 95 & $\mathrm{C}_{8} \mathrm{H}_{6} \mathrm{CL}_{4} \mathrm{O}_{2}$ & 275 \\
14.687 & 0.18 & Tetradecadien-3-one,1,13- & 86 & $\mathrm{C}_{14} \mathrm{H}_{24} \mathrm{O}$ & 208 \\
14.984 & 0.66 & Hexadecanal & 96 & $\mathrm{C}_{16} \mathrm{H}_{32} \mathrm{O}$ & 240 \\
15.277 & 1.09 & Pentatriacontane & 91 & $\mathrm{C}_{35} \mathrm{H}_{72}$ & 492 \\
15.491 & 0.88 & Hexatriacontane & 93 & $\mathrm{C}_{36} \mathrm{H}_{74}$ & 506 \\
15.723 & 11.67 & 4-octadecyl- Morpholine & 95 & $\mathrm{C}_{22} \mathrm{H}_{45} \mathrm{NO}$ & 339 \\
15.877 & 20.15 & N,N-dimethyl-1-pentadecanamine & 96 & $\mathrm{C}_{17} \mathrm{H}_{37} \mathrm{~N}$ & 255 \\
16.462 & 4.67 & Pentadecanoic acid & 93 & $\mathrm{C}_{15} \mathrm{H}_{30} \mathrm{O}_{2}$ & 242 \\
17.764 & 5.37 & Morpholine, 4-octadecyl- & 95 & $\mathrm{C}_{22} \mathrm{H}_{45} \mathrm{NO}_{3}$ & 339 \\
17.932 & 0.64 & Phytol isomer & 96 & $\mathrm{C}_{20} \mathrm{H}_{40} \mathrm{O}$ & 296 \\
18.140 & 2.89 & $9,12-$-octadecadienoic acid (z,z)- & 90 & $\mathrm{C}_{18} \mathrm{H}_{32} \mathrm{O}_{2}$ & 280 \\
18.176 & 7.05 & cis-9-hexadecenal & 92 & $\mathrm{C}_{16} \mathrm{H}_{30} \mathrm{O}$ & 238 \\
18.361 & 0.49 & 10-methoxy-nb-.alpha.-methylcorynantheo & 86 & $\mathrm{C}_{21} \mathrm{H}_{29} \mathrm{~N}_{2} \mathrm{O}_{2}$ & 341 \\
18.522 & 0.28 & Hecogenin & 78 & $\mathrm{C}_{27} \mathrm{H}_{42} \mathrm{O}_{4}$ & 430 \\
19.659 & 3.97 & Morpholine, 4-octadecyl- & 95 & $\mathrm{C}_{22} \mathrm{H}_{45} \mathrm{NO}_{3}$ & 339 \\
21.539 & 3.41 & 1,2-propanediol, 3-benzyloxy-1,2-diacetyl- & 79 & $\mathrm{C}_{14} \mathrm{H}_{18} \mathrm{O}_{5}$ & 266 \\
24.630 & 23.6 & Tetracontane & 96 & $\mathrm{C}_{40} \mathrm{H}_{82}$ & 563 \\
38.193 & 1.38 & Phytol, acetate & $\mathrm{C}_{22} \mathrm{H}_{42} \mathrm{O}_{2}$ & 338 \\
\hline
\end{tabular}

Table 4 Antimicrobial activity of volatile organic compounds produced by Muscodor camphora after 3 days exposure.

\begin{tabular}{lll}
\hline Test Organism & Repository & Growth Inhibition (\%) \\
\hline FUNGI & & \\
Alternaria alternata & MTCC 5432 & $57.3 \pm 2.7$ \\
Arthrinium phaeospermum & DBT, TU & $27.1 \pm 1.8$ \\
Botrytis cinerea & MTCC 359 & $33.8 \pm 1.5$ \\
Cercospora beticola & MSU, USA & $57.6 \pm 2.8$ \\
Colletotrichum gloeosporioides & MTCC 9623 & $59.2 \pm 2.7$ \\
Fusarium solani & DBT, TU & $19.2 \pm 1.7$ \\
Fusarium oxysporum & DBT, TU & $13.2 \pm 2.0$ \\
Lasiodiplodia theobromae & DBT, TU & $70.8 \pm 3.6$ \\
Rhizoctonia solani & MTCC 4634 & $61.4 \pm 3.9$ \\
YEASTS & & \\
Candida albicans & MTCC 854 & $30 \pm 0.8$ \\
Candida glabrata & MTCC 3019 & $50 \pm 2.4$ \\
Candida vishwanathii & MTCC 1629 & $50 \pm 1.7$ \\
BACTERIA & & \\
Pseudomonas aeruginosa & MTCC 3541 & $70 \pm 4.1$ \\
Staphylococcus aureus & MTCC 96 & $50 \pm 3.4$ \\
Staphylococcus epidermidis & MTCC 2639 & $60 \pm 2.9$ \\
\hline
\end{tabular}

*MTCC: Microbial Type Culture Collection, Chandigarh; DBT, TU: Department of Biotechnology, Thapar University, Patiala; MSU: Montana State University, USA 

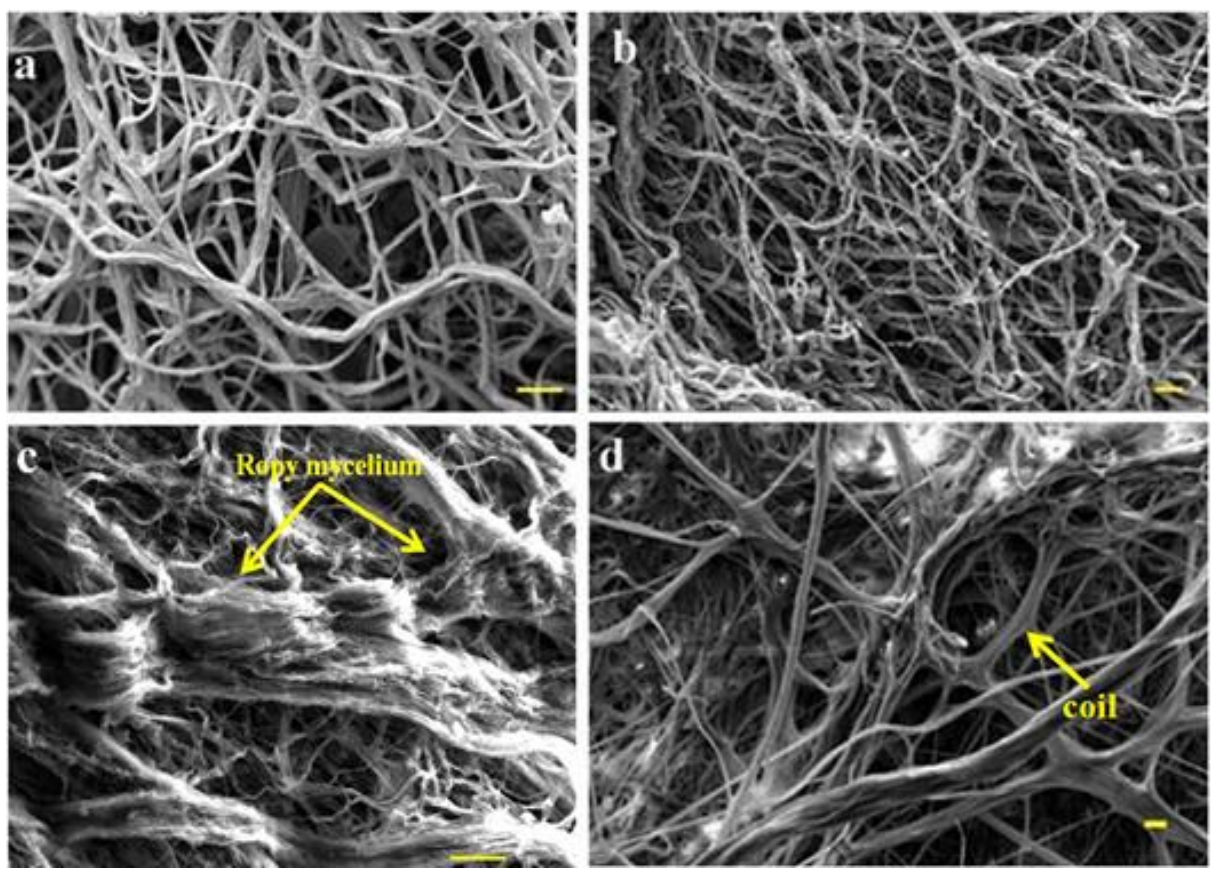

Figure 3 - Scanning electron micrograph of ten day old Muscodor camphora. a-b Sterile hyphal web, c Ropy mycelium, d Hyphal coil. Bars $=10 \mu \mathrm{m}$.

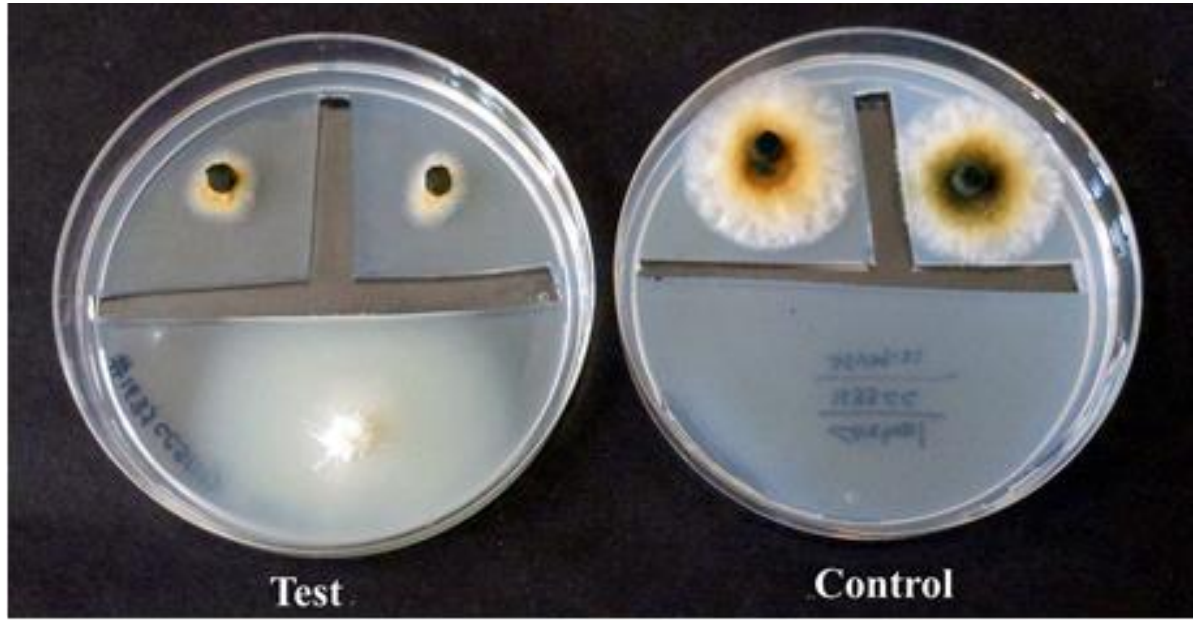

Figure 4 - Bioassay of VOCs produced by M. camphora. Inoculation with Muscodor camphora (left, lower colony) inhibited growth of Alternaria alternata (inoculation in the upper quarter) as compared to the control (right). Pictures were taken 72 hours post volatile exposure.

\section{Volatile analysis of M. camphora}

Muscodor camphora produced a mixture of 18 volatile compounds which were tentatively identified by comparing the GC/MS spectra in the NIST Database (Table 3). Of all the compounds produced, tetracontane was the most abundant covering $23.63 \%$ of all the compounds present in the air space of the plate. Other important volatiles produced were N, N-dimethyl-1-pentadecanamine $(21.5 \%)$, 4-Octadecylmorpholine $(22.2 \%)$ and cis-9 hexadecanal $(7.1 \%)$ and decanoic acid decyl ester $(5.0 \%)$. Most of the volatiles produced by M. camphora are unique and have not been reported by any other Muscodor species so far.

\section{Bioassay of VOCs produced by M. camphora}

The VOCs produced by $M$. camphora exhibits inhibitory activity against the tested spectrum of bacteria, yeast and fungi. An array of 15 microorganisms was tested, out of which the growth of 
Table 5 Comparison of M. camphora with other species of Muscodor ${ }^{\#}$.

\begin{tabular}{|c|c|c|c|c|c|c|c|c|}
\hline \multirow[t]{2}{*}{ Muscodor species (year) } & \multirow[t]{2}{*}{ Host Plant } & \multirow[t]{2}{*}{ Location } & \multirow[t]{2}{*}{ Mycelial growth } & \multirow{2}{*}{$\begin{array}{l}\text { Pigment } \\
\text { production }\end{array}$} & \multirow[t]{2}{*}{ Major VOCs } & \multicolumn{3}{|c|}{ Bioactivity* $^{*}$} \\
\hline & & & & & & $\mathbf{a}$ & $\mathbf{b}$ & c \\
\hline M. albus (2001) & C. zeylanicum & Honduras, S. America & Rope Like & None & $\begin{array}{l}\text { Propanoic acid, 2-methyl, } \\
\text { 2-nonanone }\end{array}$ & + & + & - \\
\hline M. vitigenus (2002) & P. paullinioides & Peruvian Amazon & Rope Like & None & Naphthalene (only) & - & - & + \\
\hline M. roseus (2002) & G. pteridifolia & Northern Australia & $\begin{array}{l}\text { Rope-like, erumpent } \\
\text { pie-shaped sectors }\end{array}$ & $\begin{array}{c}\text { Red } \\
\text { (in light) }\end{array}$ & $\begin{array}{l}\text { 2-butenoic acid, Ethyl } \\
\text { ester, 1,2,4-tri-methyl- } \\
\text { benzene, 2-nonadiene }\end{array}$ & + & + & - \\
\hline M. crispans (2008) & A. ananassoides & Bolivian Amazon & $\begin{array}{l}\text { Rope-like with } \\
\text { cauliflower-like } \\
\text { bodies }\end{array}$ & $\begin{array}{l}\text { Raddish } \\
\text { (in light) }\end{array}$ & Propanoic acid, 2-methyl & + & + & - \\
\hline M.yucatanensis (2009) & B. simaruba & $\begin{array}{l}\text { Yucatan peninsula, } \\
\text { Mexico }\end{array}$ & $\begin{array}{l}\text { Rope-like with coiled } \\
\text { hyphae }\end{array}$ & None & $\begin{array}{l}\text { 1R,4S,7S,11R-2,2,4,8- } \\
\text { Tetramethyl-tricyclo } \\
{[5.3 .1 .0(4,11)] \text { undec-8-ene, }} \\
\text { Caryophyllene, }\end{array}$ & + & - & - \\
\hline M. fengyangensis (2010) & A. chinesis & $\begin{array}{l}\text { Fengyangshan Nature } \\
\text { reserve, China }\end{array}$ & $\begin{array}{l}\text { Rope-like with coiled } \\
\text { hyphae }\end{array}$ & Yellow & $\begin{array}{l}\text { Naphthalene \& azulene } \\
\text { derivatives }\end{array}$ & + & + & - \\
\hline M. cinnamomi (2010) & C. bejolghota & $\begin{array}{l}\text { Doi suthep-pui, National } \\
\text { Park, Thailand }\end{array}$ & $\begin{array}{l}\text { Rope-like with coiled } \\
\text { hyphae }\end{array}$ & $\begin{array}{l}\text { Pale Orange } \\
\text { (in light) }\end{array}$ & $\begin{array}{l}\text { Propanoic acid, 2-methyl, } \\
\text { Methyl ester, } \beta \text {-humulene }\end{array}$ & + & + & - \\
\hline M. sutura (2012) & P. trifidi & $\begin{array}{l}\text { Columbian tropical } \\
\text { Pacific rainforest }\end{array}$ & $\begin{array}{l}\text { Rope-like bands } \\
\text { extra-cellular bodies }\end{array}$ & $\begin{array}{l}\text { Reddish } \\
\text { (in Dark) }\end{array}$ & $\begin{array}{l}\text { Propanoic acid, 2-methyl, } \\
\text { Thujopsene }\end{array}$ & + & - & - \\
\hline M. musae (2013) & M. acuminata & Doi suthep-pui, Thailand & $\begin{array}{l}\text { Rope-like with coils } \\
\text { structure }\end{array}$ & None & 2-methylpropanoic acid & + & + & - \\
\hline M. oryzae (2013) & O. rufipogon & Chiang Mai, Thailand & $\begin{array}{l}\text { Rope-like with coils } \\
\text { structure }\end{array}$ & Orange & 3-Methylbutan-1-ol & + & + & - \\
\hline M. suthepensis (2013) & C. bejolghota & $\begin{array}{l}\text { Doi-Suthep Pui, } \\
\text { Thailand }\end{array}$ & $\begin{array}{l}\text { Rope-like with coils } \\
\text { structure }\end{array}$ & $\begin{array}{l}\text { Pale pink } \\
\text { (in light) }\end{array}$ & 2-methylpropanoic acid & + & + & - \\
\hline M. equiseti (2013) & E. debile & Chiang Mai, Thailand & $\begin{array}{l}\text { Rope-like coils and } \\
\text { swollen cell }\end{array}$ & None & 2-methylpropanoic acid & - & + & - \\
\hline
\end{tabular}




\section{Table 5 (Continue)}

\begin{tabular}{|c|c|c|c|c|c|c|c|c|}
\hline \multirow[t]{2}{*}{ Muscodor species (year) } & \multirow[t]{2}{*}{ Host Plant } & \multirow[t]{2}{*}{ Location } & \multirow[t]{2}{*}{ Mycelial growth } & \multirow{2}{*}{$\begin{array}{l}\text { Pigment } \\
\text { production }\end{array}$} & \multirow[t]{2}{*}{ Major VOCs } & \multicolumn{3}{|c|}{ Bioactivity* } \\
\hline & & & & & & $\mathbf{a}$ & $\mathbf{b}$ & c \\
\hline M. kashayum (2013) & A. marmelos & $\begin{array}{l}\text { Wayanad wild life } \\
\text { sanctuary, Kerala, India }\end{array}$ & Rope like & None & $\begin{array}{l}\text { 3-cyclohexen-1-ol,1-(1,5- } \\
\text { dimethyl-4-hexenyl)-4- } \\
\text { methyl; 1,6- } \\
\text { dioxacyclododecane- }\end{array}$ & + & + & - \\
\hline M. darjeelingensis (2014) & C. camphora & $\begin{array}{l}\text { Darjeeling, West Bengal, } \\
\text { India }\end{array}$ & $\begin{array}{l}\text { Rope like with } \\
\text { cauliflower like } \\
\text { structures }\end{array}$ & None & $\begin{array}{l}\text { 2, 6-Bis }(1,1- \\
\text { dimethylethyl)-4-(1- } \\
\text { oxopropyl) } \\
\text { phenol, 1, 6- } \\
\text { Dioxacyclododecane-7, 12- } \\
\text { dione }\end{array}$ & + & + & - \\
\hline M. strobelii (2014) & C. zeylanicum & $\begin{array}{l}\text { BRT wildlife sanctuary, } \\
\text { Karnataka, India }\end{array}$ & $\begin{array}{l}\text { Rope-like, slimy; } \\
\text { Zinnia bud-like } \\
\text { bodies }\end{array}$ & $\begin{array}{l}\text { Pale Yellow } \\
\text { (in light) }\end{array}$ & $\begin{array}{l}\text { 4-octadecyl-morpholine, } \\
\text { Tetraoxapropellan, }\end{array}$ & + & + & - \\
\hline M. tigerii (2015) & C. camphora & $\begin{array}{l}\text { Darjeeling, West Bengal, } \\
\text { India }\end{array}$ & $\begin{array}{l}\text { Rope like with } \\
\text { swollen hyphae and } \\
\text { coils }\end{array}$ & Brown & $\begin{array}{l}\text { 4-Octadecylmorpholine, } 1 \text { - } \\
\text { Te t r a d e c a n a m i n e, } \\
\text { N,N - d i m e t h y } 1\end{array}$ & + & + & - \\
\hline M. ghoomensis (2016) & C. camphora & $\begin{array}{l}\text { Darjeeling, West Bengal, } \\
\text { India }\end{array}$ & $\begin{array}{l}\text { Rope-like with } \\
\text { structure coils and } \\
\text { grape like structure }\end{array}$ & Pale yellow & $\begin{array}{l}\text { 4-octadecylmorpholine, } 1 \text { - } \\
\text { nonadecamine-N.Ndimethyl }\end{array}$ & + & + & \\
\hline M. indica (2016) & C. camphora & $\begin{array}{l}\text { Darjeeling, West Bengal, } \\
\text { India }\end{array}$ & $\begin{array}{l}\text { Rope-like with coils } \\
\text { structure }\end{array}$ & Pale yellow & $\begin{array}{l}\text { 1, 6-dioxacyclododecane- } \\
\text { 7,12-dione; 4- } \\
\text { octadecylmorpholine; } \\
\text { Squalene; Pogostol }\end{array}$ & + & + & - \\
\hline M. camphora (2017) & C. camphora & $\begin{array}{l}\text { Darjeeling, West Bengal, } \\
\text { India }\end{array}$ & $\begin{array}{l}\text { Rope like with } \\
\text { coiled structures }\end{array}$ & None & $\begin{array}{l}\text { Tetracontane, 4-octadecyl } \\
\text { morpholine }\end{array}$ & + & + & - \\
\hline
\end{tabular}


three fungal pathogens Colletotrichum gloeosporioides, Rhizoctonia solani and Lasiodiplodia theobromae were suppressed by $60-70 \%$ while the growth of other fungal pathogens in the test panel exhibited inhibition in range of $13-57 \%$. M. albus cz620 remains unaffected to VOCs. The growth of candida isolates was also retarded by $30-50 \%$ while Staphylococcus aureus, Staphylococcus epidermidis and Pseudomonas aeruginosa exhibited 50-70\% inhibition respectively when exposed to the VOCs (Table 4, Fig. 4). Muscodor camphora exhibits a fungistatic and bacteriostatic activity, it does not completely kill the microorganisms in the test panel.

\section{Discussion}

Identification of Muscodor species till date has been based on three aspects- cultural characteristics (morphotaxomony), Microscopic and SEM based hyphal characteristics, ITS and VOC profile (Strobel 2011; Meshram et al. 2013; Saxena et al. 2015; Siri-udom et al. 2017). In the present investigation, also, \#CCSTITD 1639 was devoid of any reproductive structures like other Muscodor species, light microscopically also it exhibited rope like hyphal strands which branched at right angles. Further the culture plate exhibited a volatile fruity type smell which indicated that it emanated volatile organic compounds. Scanning electron microscopy further confirmed that true features of Muscodor exhibiting a ropy mycelium, which branched at right angles.

Morphologically, Muscodor camphora is different from M. cinnamomi, M. sutura, M. crispans which exhibit a cauliflower like sterile structure and possesses ropy coiled mycelia. M. yucatanensis, $M$. equiseti and $M$. tigerii has a ropy structure with swollen hyphae whereas Muscodor albus, M. strobelii only exhibits a ropy mycelium without any hyphal coils hence making it different from $M$. camphora. Muscodor roseus has a dense rose colored mycelium making it remarkably dissimilar from M. camphora. Further VOC analysis of CCSTITD\#1639 exhibited a distinct profile when compared to the reported species of Muscodor. The volatiles produced by the fungus can be broadly categorized into three categories, steroids, terpenoids and aliphatic and aromatic compounds. The first category of compounds comprised of steroids like hecogenin which possess antifungal activity (Jin et al. 2003). The second category includes phytol and squalene which are terpenoidal in nature having isoprene units in them and are known antibacterial. Phytol is also reported to possess antinociceptive and antioxidant properties. The third category comprised of aliphatic and aromatic compounds having polar groups in them like amines, ethers, phenols acids and their derivatives e.g. 4-octadecylmorpholine, N, N-dimethyl-1-pentadecanamine. Earlier reports suggest that these compounds possess antimicrobial activity. Certain linear hydrocarbons like tetracontane, hexatriacontane and pentatricontane were alsoproduced in abundance by CCSTITD \#1639. Hexatriacontane possess radical scavenging property (Marrufo et al. 2013). An endophytic fungus belonging to pleosporaceae, bn12 isolated from $C$. camphora has also been reported to produce mixture volatile metabolites including borneol, indoles, amines, alcohol and acids (Chen et al. 2011). The VOCs profile of M. camphora is different from the previously reported Muscodor species which dominantly produces esters of propanoic acid, azuelene, naphthalene derivatives and thujopsene. Most of the volatiles produced by $M$. camphora are unique and thus suggesting it to be a new species of Muscodor.

This was further substantiated by antimicrobial bioassay of the VOC's of CCSTITD\#1639, which exhibited a fungistatic and bacteriostatic activity as compared to other Muscodor species which exhibited a potent fungicidal and bactericidal activity. Muscodor species including M. albus, M. crispans, M. equiseti, M. fengyangensis, M. musae, M. kashayum, exhibited both antifungal and antibacterial activity whereas $M$. sutura and $M$. yucatanensis only showed antifungal activity (Suwannarach et al. 2013, Meshram et al. 2014). Further, M. albus, M. crispans and M. sutura completely inhibited the growth of two of the most important pathogens i.e. Pythium and Phytophthora species whereas M. kashayum, M. suthepensis and M. equiseti also checked the growth of Fusarium spp., that are potential plant pathogen leading to huge crop loss. Similarly, the VOCs of M. crispans completely inhibited the growth of drug resistant Mycobacterium tuberculosis (Strobel 2001, Mitchell et al. 2010, Meshram et al. 2013, Suwannarach et al. 2013). 
Final molecular phylogenetic analysis corroborated the earlier findings based on morphological and volatile studies that CCSTITD \#1639 is a novel species of Muscodor, wherein it distinctly clustered basal to the clade 1 confirming it to be a distinct species of Muscodor isolated from $C$. camphora (Fig.2). This was further substantiated by the DNA polymorphism data of the ITS region (Table 1).

\section{Conclusion}

CCSTITD \#1639 exhibited a variety of common features shared by Muscodor species; however, at molecular level it possesses certain distinguishing features, a unique volatile gas chemistry and differing antimicrobial spectrum (Table 5). Thus, CCSTITD \#1639 is introduced as M. camphora, a novel species in genus Muscodor with antimicrobial property.

\section{Acknowledgements}

We thank Department of Biotechnology (National Biodiversity Development Board) for sponsoring the project no. BT/PR/10083/NDB/52/95/2007. Vineet Meshram is thankful to University Grants Commission, New Delhi, India for granting Rajiv Gandhi fellowship. Dr. Sanjai Saxena acknowledges Prof. Dr. Gary Strobel, MSU-Bozeman, USA for providing an M. albus cz620 type strain, plant pathogenic fungi and for constructive discussions. We also gratefully acknowledge the kind help of Dr. Ruchita Pal from AIRF, JNU and Mr. Aatish Verma from SAI labs, Thapar University for SEM analysis and Shri Ajay Kumar from AIRF, JNU, New Delhi for GC/MS analysis.

\section{References}

Arnold AE, Maynard Z, Gilbert GS. 2001- Fungal endophytes in dicotyledonous neotropical trees: patterns of abundance and diversity. Mycological Research 105, 1502-1507.

Chen M, Yang L, Li Q, Shen Y et al. 2011 - Volatile metabolites analysis and molecular identification of endophytic fungi bn12 from Cinnamomum camphora Chvar. borneol. China Journal of Chinese Materia Medica 36, 3217-3221.

Daisy BH, Strobel GA, Castillo U, Ezra D et al. 2002 - Naphthalene, an insect repellent, is produced by Muscodor vitigenus, a novel endophytic fungus. Microbiology148, 3737-3741.

Ezra D, Hess WM, Strobel GA. 2004 - New endophytic isolates of Muscodor albus, a volatile antibiotic-producing fungus. Microbiology 12, 4023-4031.

Ezra D, Skovorodnikova J, Kroitor-Keren T, Denisov Y, Liarzi, O. 2010 - Development of methods for detection and Agrobacterium-mediated transformation of the sterile, endophytic fungus Muscodor albus. Biocontrol Science and Technology 20, 83-97.

Fu YX, Li WH. 1993 - Statistical tests of neutrality of mutations. Genetics 133, 693-709.

Gabler MF, Fassel R, Mercier J, Smilanick JL. 2006 - Influence of temperature, inoculation interval, and dosage on biofumigation with Muscodor albus to control postharvest gray mold on grapes. Plant Disease 90, 1019-1025.

Gonzalez MC, Anaya AL, Glenn AE, Macias-Rubalcava ML et al. 2009 - Muscodor yucatanensis, a new endophytic ascomycete from Mexican chakah, Bursera simaruba. Mycotaxon 110, 363372.

Gutierrez RMP, Gonzalez AMN, Ramirez AM. 2012 - Compounds derived from endophytes: a review of phytochemistry and pharmacology. Current Medicinal Chemistry 19, 2992-3030.

Hyde KD, Soytong K. 2008 - The fungal endophyte dilemma. Fungal Diversity 33, 163-173.

Jin JM, Liu XK, Yang CR. 2003 - Three new hecogenin glycosides from fermented leaves of Agave Americana. Journal of Asian Natural Products and Research 5, 95-103.

Kudalkar P, Strobel G, Hasan SRU, Geary G, Sears J. 2012 - Muscodor sutura, a novel endophytic fungus with volatile antibiotic activities. Mycoscience 53, 319-32.

Librado P, Rozas J. 2009 - DnaSP v5: a software for comprehensive analysis of DNA polymorphism data. Bioinformatics 25, 1451-1452. 
Marrufo T, Nazzaro F, Mancini E, Fratianni F et al. 2013 - Chemical Composition and Biological Activity of the Essential Oil from Leaves of Moringa oleifera Lam. Cultivated in Mozambique. Molecules 18, 10989-11000.

Mercier J, Santamaria JIJ, Guerra PT. 2007- Development of the volatile producing fungus Muscodor albus Worapong, Strobel \& Hess as a novel antimicrobial bio-fumigant. Revista Mexicana de Fitopatología 25, 173-179.

Mercier J, Smilanick JL. 2005 - Control of green mold and sour rot of stored lemon by biofumigation with Muscodor albus. Biological Control 32, 401-407.

Meshram V, Gupta M, Saxena S. 2016 - Muscodor ghoomensis and Muscodor indica: new endophytic species based on morphological features, molecular and volatile organic analysis from northeast India. Sydowia 67, 133-146.

Meshram V, Kapoor N, Saxena S. 2013 - Muscodor kashayum sp. nov. - a new volatile antimicrobial producing endophytic fungus. Mycology 4, 196-204.

Meshram V, Saxena S, Kapoor N. 2014 - Muscodor strobelii, a new endophytic species from south India. Mycotaxon 128, 93-104.

Mitchell A, Strobel G, Hess W, Vargas P, Ezra D. 2008 - Muscodor crispans, a novel endophyte from Ananas ananassoides in the Bolivian Amazon. Fungal Diversity 31, 37-43.

Murli TS, Suryanarayan TS, Venkatesan G. 2007 - Fungal endophyte communities in true topical forest of southern India: diversity and host affiliation. Mycological Progress 6, 191-199.

Nei M, Kumar S. 2000 - Molecular evolution and phylogenetics. Oxford University Press, New York.

Nilsson RH, Kristiansson E, Ryberg M, Hallenberg N, Larsson KH. 2008 - Intraspecific ITS variability in the Kingdom Fungi as expressed in the international sequence databases and its implications for molecular species identification. Evolutionary Bioinformatics Online 4, 193201.

Peay KG, Bidartondo MI, Arnold AE. 2010 - Not every fungus is everywhere: scaling the biogeography of fungal-plant interaction across roots shoots and ecosystem. New Phytologist $185,878-882$.

Rodriquez RJ, White JF Jr, Arnold AE, Redman RS. 2008 - Fungal endophytes: diversity and functional role. New Phytologist 182, 314-330.

Saitou N, Nei M. 1987 - The Neighbour-Joining Method: A new method for reconstructing phylogenetic trees. Molecular Biology and Evolution 4, 406-425.

Saxena S, Meshram V, Kapoor N. 2014 - Muscodor darjeelingensis, a new endophytic fungus of Cinnamomum camphora collected from northeastern Himalayas. Sydowia 66, 55-67.

Saxena S, Meshram V, Kapoor N. 2015 - Muscodor tigerii sp. nov. Volatile antibiotic producing endophytic fungus from the northeastern Himalayas. Annals of Microbiology 65, 47-57.

Schnabel G, Mercier J. 2006 - Use of a Muscodor albus pad delivery system for the management of brown rot of peach in shipping cartons. Postharvest Biology and Technology 42, 121-123.

Schulz B, Boyle C, Draeger S, Rommert AK, Krohn K. 2002 - Endophytic fungi: a source of biologically active secondary metabolites. Mycological Research 106, 996-1004.

Schulz B, Boyle C. 2005 - The endophytic continuum. Mycological Research 109, 661-686.

Schulz B, Rommert AK, Dammann U, Aust HJ, Strack D. 1999 - The endophyte-host interaction: a balanced antagonism? Mycological Research 103, 1275-1283.

Siri-udom S, Suwannarach N and Lumyong S. 2017- Applications of volatile compounds acquired from Muscodor heveae against white root rot diseases in rubber trees (Hevea brasiliensis Mull. Arg) and relevant Allelopathy effects. Fungal Biology doi: 10.1016/j.funbio.2017.03.004

Stinson AM, Zidack NK, Strobel GA, Jacobsen BJ. 2003 - Mycofumigation with Muscodor albus and Muscodor roseus for control of seedling diseases of sugar beet and Verticillium wilt of eggplant. Plant Disease 87, 1349-135.

Strobel GA, Dirske E, Sears J, Markworth C. 2001 - Volatile antimicrobials from Muscodor Albus, a novel endophytic fungus. Microbiology 147, 2943-295. 
Strobel G, Daisy B. 2003 - Bioprospecting for microbial endophytes and their natural products. Microbial Molecular Biology Reviews 4, 491-502.

Strobel G. 2006 - Muscodor albus and its biological promise. Journal of Industrial Microbiology and Biotechnology 33, 514-522.

Strobel GA, Katreena K, Hess WM, Sears J et al. 2007 - Muscodor Albus E-6, An endophyte of Guazuma ulmifolia making volatile antibiotics: isolation, characterization and experimental establishment in host plant. Microbiology 153, 2613-2620.

Strobel G. 2011- Muscodor species- endophytes with biological promise. Phytochemistry Reviews $10,165-172$

Suryanarayanan TS, Thirunavukkarasu N, Govindarajulu MB, Sasse F et al. 2009 - Fungal endophytes and bioprospecting. Fungal Biology and Reviews 23, 9-19.

Suwannarach N, Bussaban B, Hyde KD, Lumyong, S 2010 - Muscodor cinnamomi, a new endophytic species from Cinnamomum bejolghota. Mycotaxon 114, 15-23.

Suwannarach N, Kumla J, Bussaban B, Hyde KD et al. 2013 - Molecular and morphological evidence support four new species in the genus Muscodor from northern Thailand. Annals of Microbiology 63, 1341-1351.

Suwannarach N, Kumla J, Matsui K, Lumyong S. 2015 - Characterization and efficacy of Muscodor cinnamomi in promoting plant growth and controlling Rhizoctonia root rot in tomatoes. Biological Control 90, 25-33.

Tajima F. 1989 - Statistical method for testing the neutral mutation hypothesis by DNA polymorphism. Genetics 123, 585-595.

Tamura K, Peterson D, Peterson N, Stecher G et al. 2011 - MEGA5: Molecular evolutionary genetics analysis using maximum likelihood, evolutionary distance, and maximum parsimony methods. Molecular Biology and Evolution 28, 2731-2739.

Worapong J, Strobel GA, Daisy B, Castillo U et al. 2002 - Muscodor roseus anam. sp. nov., an endophyte from Grevillea pteridifolia. Mycotaxon 81, 463-475.

Worapong J, Strobel GA, Ford EJ, Li JY et al. 2001 - Muscodor albus anam. nov., an endophyte from Cinnamomum zeylanicum. Mycotaxon 79, 67-79.

Zhang CL, Wang GP, Mao LJ, Komon- Zelazowska M et al. 2010 - Muscodor fengyangensis sp. nov. from south east China: morphology, physiology and production of volatile compounds. Fungal Biology 114, 797-808.

Zhang HW, Song YC, Tan X. 2006 - Biology and chemistry of endophytes. Natural Product Reports $18,448$. 